\title{
OBITUARY
}

\section{H. WICKENS, I.S.O.}

ThE news of the death, at the age of 67 , of Charles Henry Wickens, of Melbourne, Australia, will have been received with deep regret, especially by those British actuaries who had the privilege of making his acquaintance at the Eighth International Congress of Actuaries in London in 1927. During this, his only visit to Europe, he represented Australia both at an Imperial Conference and at Geneva. He thus became well known to his collcagues in the Home Government service, who appreciated his personal charm no less than his great ability in a wide range of subjects. For the last eight years his health had been seriously impaired and he had lived in retirement, but, prior to the onset of this illness, he had a most distinguished career in the public service in Australia, and at the time of his retirement in 1932 he occupied the position of Commonwealth Statistician and Actuary.

Born in Victoria in 1872 , Wickens entered the Western Australian Civil Service at the age of 25 as a statistician. On the establishment of the Commonwealth Bureau of Census and Statistics in 1906 he transferred to that office and in 1922, on the death of his chief, Sir George Knibbs, he succeeded to the post of Commonwealth Statistician. Two years later, recognition was made of the fact that his duties were as much actuarial as statistical by expanding his title to Commonwealth Statistician and Actuary.

Wickens was an indefatigable worker, and the list of the tasks which fell to him during his official career, and which he discharged with thoroughness and ability, is a formidable one. Amongst other things he was responsible for the supervision of the Australian population censuses of 1911 and 1921 and for the census of wealth taken in 1915, and he compiled Life Tables, based on the I9I1 and I92 I censuses, which have largely supplanted English Life Tables in Australian life assurance work. He was also largely responsible for the formulation of the existing scheme of superannuation for the Commonwealth Public Service, and served as the actuarial member of the Commonwealth Superannuation Board. In addition to his normal official duties he was called upon to give evidence before almost every Australian Royal Commission set up to consider economic or financial matters between 1922 and 1931 .

Wickens became a Fellow of the Institute in 1920, having qualified as an. Associate many years earlier. In 1905 he was awarded the Messenger Prize for an essay on methods of ascertaining mortality 
rates amongst different classes of the population, which will be familiar to the students of those days. Subsequently he made a number of contributions to the foumal, and in $193^{\circ}$ submitted a paper to the Institute on Australian Mortality. G. S. W. E.

Ralph Bernard Gough, Student of the Institute, H.M.S. Exmouth. Lost at Sea, January 1940.

Arnold Boynton Hall, Student of the Institute, H.M.S. Exmouth. Lost at Sea, January 1940. 